\title{
RETENSI HASIL BELAJAR DENGAN METODE VERBAL DIBANDINGKAN METODE KOMBINASI VERBAL - VISUAL PADA MAHASISWA PROGRAM STUDI KEPERAWATAN POSO
}

\section{A Comparison of Learning Result Retention With Verbal Method and Verbal-Visual Combination Method Towards Nursing Program Students in Poso}

\author{
FRANSISCA NOYA \\ Poltekkes Kemenkes Palu \\ (fransiscanoya@yahoo.co.id, 081221934992)
}

\begin{abstract}
ABSTRAK
Penelitian ini bertujuan untuk mengetahui perbedaan pembelajaran dengan metode verbal dan metode kombinasi verbal-visual terhadap retensi hasil belajar mahasiswa semester IV Program Studi Keperawatan Poso mengenai Pencegahan Infeksi. Penelitian ini merupakan penelitian eksperimental dengan pendekatan prospektif. Sample sebanyak 68 Mahasiswa yang dipilih dengan menggunakan sistem acak sederhana. Mahasiswa kemudian dibagi menjadi dua kelompok yaitu kelompok A dan kelompok B, masing-masing berjumlah 34 orang. Metode penyajian kombinasi verbal - visual dilakukan pada kelompok A dan metode penyajian verbal dilakukan pada kelompk B. Data dianalisis dengan menggunakan Uji " $\mathrm{t}$ " pada taraf kepercayaan 95\%. Penelitian ini menunjukkan bahwa pada metode verbal ada peningkatan nilai rata-rata sebesar 555,338 atau $118,57 \%$. Pada metode kombinasi verbal-visual ada peningkatan nilai rata-rata sebesar 1986,68 atau 446,52\%. Sehingga, dapat disimpulkan, terdapat perbedaan yang bermakna antara retensi hasil pembelajaran yang menggunakan verbal dibanding kombinasi verbal-visual.
\end{abstract}

Kata kunci : Verbal-visual, verbal, retensi hasil belajar

\begin{abstract}
This research aims to determine the differences between learning with verbal methods and verbal-visual combination methods towards the retention of learning result of the fourth semester students of nursing program in Poso. This research is an experimental study with a prospective approach. A sample were 68 students and selected using a simple random system. Students were then divided into two groups, which were group A and group B, consisted of 34 people. The verbal - visual combinations method was tested on group $A$ and the verbal presentation method was on group $B$. The data were analyzed using the " $t$ " test at the $95 \%$ of confidence level. This research shows that there is an increase on the verbal method with the average value of 555,338 or $118.57 \%$, while in the verbalvisual combination method, it increase in the average value of 1986.68 or $446.52 \%$. So, it can be concluded, there is a significant difference between learning result retension with verbal method and verbal-visual combinations method.
\end{abstract}

Key Words: Verbal-visual, verbal, retention of learning outcomes. 


\section{PENDAHULUAN}

Belajar adalah kegiatan yang berproses dan merupakan unsur yang sangat fundamental dalam setiap penyelenggaraan jenis dan jenjang pendidikan. Skinner seperti berpendapat bahwa belajar adalah suatu proses adaptasi (penyesuaian tingkah laku) yang berlangsung secara progresif. Sedangkan Chaplin membatasi belajar dengan dua macam rumusan. Rumusan pertama bahwa belajar adalah perolehan perubahan tingkah laku yang relatif menetap sebagai akibat latihan dan pengalaman. Rumusan kedua belajar ialah proses memperoleh respons-respons sebagai akibat adanya latihan khusus ${ }^{(1)}$.

Belajar adalah key term (istilah kunci) yang paling vital dalam setiap usaha pendidikan sehingga tanpa belajar sesungguhnya tidak pernah ada pendidikan. Ini berarti, bahwa berhasil atau gagalnya pencapaian tujuan pendidikan itu amat tergantung pada proses belajar yang dialami siswa ketika ia berada di sekolah maupun di lingkungan rumah atau keluarga sendiri.

Bukti bahwa seseorang telah melakukan perbuatan belajar adalah akan terlihatnya perubahan dalam salah satu atau beberapa aspek tingkah laku pada orang tersebut. Setiap proses belajar mengajar selalu menghasilkan hasil belajar. Yang menjadi petunjuk bahwa suatu proses belajar mengajar dianggap berhasil adalah adanya daya ingat mahasiswa terhadap bahan pengajaran yang diajarkan, mencapai prestasi tinggi, serta berperilaku yang digariskan dalam tujuan pengajaran/ instruksional khusus (TIK) oleh siswa, baik secara individual maupun kelompok. Namun demikian, indikasi yang banyak dipakai sebagai tolok ukur keberhasilan adalah daya ingat / retensi.

Retensi/ingatan adalah proses menerima, menyimpan dan mengeluarkan kembali informasi-informasi yang telah diterima melalui pengamatan, kemudian disimpan dalam pusat kesadaran (otak) setelah diberikan tafsiran ${ }^{(2)}$. Penelitian yang dilakukan oleh Mc Leish, yang mengevaluasi hasil kuliah mahasiswa, melaporkan bahwa mahasiswa hanya mengingat $40 \%$ dari informasi yang disampaikan oleh pengajar, sedangkan Magnesen melaporkan bahwa daya ingat dari apa yang dibaca hanya $10 \%$, dari mendengar $20 \%$, dengan melihat dan mendengar $30 \%$, sedang dari apa yang dikatakan dan dilakukan adalah $70 \%$.

Dalam belajar, masalah yang dihadapi adalah sampai di tingkat mana retensi hasil belajar tersebut dapat dicapai oleh mahasiswa ${ }^{(3)}$. Retensi hasil belajar yang rendah akan mengakibatkan prestasi belajar mahasiswa menurun. Dengan prestasi yang menurun maka mutu lulusan yang diharapkan tidak akan dapat terwujud ${ }^{(4)}$.

Proses retensi/ingatan banyak dipengaruhi oleh berbagai faktor yang meliputi faktor individu, faktor sesuatu yang harus diingat, dan faktor lingkungan. Dari aspek individu, proses mengingat akan lebih efektif apabila individu memiliki minat yang besar, motivasi yang kuat, memiliki metode penyajian tertentu dalam pengamatan dan pembelajaran, memiliki kondisi fisik dan 
kesehatan yang baik. Dari aspek yang harus diingat adalah sesuatu yang memiliki organisasi dan status yang jelas, mempunyai arti, mempunyai keterkaitan dengan individu, mempunyai intensitas rangsangan yang cukup kuat, dan sebagainya. Dari aspek lingkungan, proses mengingat akan lebih efektif apabila ada lingkungan yang menunjang dan terhindar dari adanya gangguan-gangguan ${ }^{(5)}$. Salah satu faktor yang mempengaruhi daya ingat adalah metode penyajian $^{(4)}$.

Pembelajaran merupakan suatu kegiatan yang melibatkan seseorang dalam upaya memperoleh pengetahuan, keterampilan dan nilai- nilai positif dengan memanfaatkan berbagai sumber untuk belajar ${ }^{(6)}$. Didalam pembelajaran seorang pengajar dapat melibatkan peserta didikanya sebagai pembelajar aktif dengan cara mempersaranai sumber belajar dan gaya belajarnya, sehingga akhirnya menghasilkan hasil belajar yang baik.

Karakteristik pemilihan media pembelajaran ini adalah bahwa peserta didik bukan hanya terfokus terhadap objek atau bentuk fisik media tersebut melainkan mereka harus terlibat aktif dalam penggunaan media tersebut dalam pembelajaran. Sehingga pembelajaran yang tercipta di dalam kelas bukanlah pembelajaran yang konvensional dan membosankan, melainkan pembelajaran yang aktif, efektif dan menyenangkan ${ }^{(7)}$. Bila siswa, belajar hanya dengan menggunakan verbal saja, maka kemampuan mengingat setelah 3 jam memperoleh informasi tersebut adalah sebanyak $70 \%$, dan setelah 3 hari maka sisa ingatannya hanya $10 \%$ dari seluruh informasi.
Bila siswa belajar hanya dengan menggunakan visual saja maka kemampuan mengingat setelah 3 jam memperoleh informasi adalah sebanyak $72 \%$, sedangkan setelah 3 hari maka sisa ingatannya hanya $20 \%$ dari seluruh informasi. Apabila mahasiswa belajar dengan menggunakan perpaduan antara visual dan verbal maka kemampuan mengingat setelah 3 jam akan mencapai $85 \%$ dari informasi yang telah ia terima dan setelah 3 hari akan mampu mengingat sebanyak $65 \%$ dari seluruh informasi $^{(5)}$. Penelitian Clarke et al (2006) menunjukkan bahwa adanya keseimbangan antara teknik verbal dan visual dapat memberikan manfaat pembelajaran yang signifikan $^{(10)}$.

\section{METODE PENELITIAN}

Penelitian Quasi Eksperimental,
dengan rancangan pretest-posttest control
group design. Populasi dalam penelitian ini adalah seluruh mahasiswa semester IV Program Studi Keperawatan Poso tahun ajaran 2007/2008 yang berjumlah 64 orang. Dalam hal ini seluruh populasi merupakan sampel penelitian. Mahasiswa berjumlah 64 orang dibagi menjadi 2 kelompok yaitu kelompok A (metode penyajian verbal) dan kelompok B (metode penyajian verbal dan visual) masingmasing 34 orang. Pembagian kedua kelompok tersebut dilakukan dengan menggunakan sistem acak sederhana, sehingga setiap individu mempunyai kesempatan yang sama untuk diambil sebagai sampel. Dilakukan pretest pada kelompok A dan kelompok B untuk menjamin komparabilitas kedua kelompok dan kemudian diuji secara statistik. Pada kedua 
kelompok dilakukan intervesi, kelompok A materi disampaikan dengan metode penyajian kombinasi verbal-visual, dan kelompok B dengan metode penyajian verbal. Pada kedua kelompok dilakukan post test. Hasil post test kelompok A dan kelompok B dibandingkan dengan uji statistik.

\section{HASIL}

Dari tabel 1 tampak tidak terdapat perbedaan yang bermakna $(p>0,05)$ antara kelompok A dan B pada variabel pre-test. Dengan demikian kedua kelompok dapat diperbandingkan. Pada Tabel 2 tampak pengetahuan retensi hasil post-test (setelah intervensi) pada kelompok A lebih baik dibanding kelompok B (rata-rata 75,29 dibanding 29,99). Secara statistik perbedaan ini bermakna $(\mathrm{p}<0,05)$. Pada tabel di 3 tampak nilai post-test yang menggunakan metode penyajian verbal lebih baik dari nilai pre-test, Terdapat peningkatan sebesar $118,57 \%$ (dari 466,66 menjadi 1019,998, dengan rata-rata meningkat sebesar $118,58 \%$ (dari 13,72 menjadi 29,99). Pada Tabel 4, tampak nilai post-test yang menggunakan metode penyajian kombinasi verbal-visual lebih baik daripada pre-tes terdapat peningkatan sebesar $446,52 \%$ (dari 573,32 menjadi 2560,00) dengan rata-rata meningkat $346,55 \%$ (dari 16,86 menjadi 75,29).
Tabel 1. Hasil Pre-Test Kelompok A (Metode penyajian kombinasi Verbal-Visual) dan Kelompok B (Metode penyajian Verbal) pada mahasiswa Program studi keperawatan Poso.

\begin{tabular}{ccc}
\hline & \multicolumn{2}{c}{ Kelompok } \\
\cline { 2 - 3 } & $\mathbf{A}$ & $\mathbf{B}$ \\
\hline $\mathrm{X}$ & 16,86 & 13,72 \\
$\mathrm{SD} 2$ & 62,51 & 40,25 \\
$\mathrm{SD}$ & 7,90 & 6,34 \\
"t" Hitung & 1,79 & $\mathrm{p}>0,05$ \\
"t" Tabel & 2,000 & \\
\hline
\end{tabular}

Sumber: Data Primer, 2018

Tabel 2. Hasil Post-Test Kelompok A (Metode penyajian kombinasi Verbal-Visual) dan Kelompok B (Metode penyajian Verbal) pada mahasiswa Program studi keperawatan Poso.

\begin{tabular}{ccc}
\hline & \multicolumn{2}{c}{ Kelompok } \\
\cline { 2 - 3 } & A & B \\
\hline X & 75,29 & 29,99 \\
SD2 & 140,66 & 137,74 \\
SD & 11,86 & 11,73 \\
"t" Hitung & 15,70 & $\mathrm{p}<0,05$ \\
"t" Tabel & 2,000 & \\
\hline
\end{tabular}

Sumber: Data Primer, 2018

Tabel 3. Peningkatan daya ingat (retensi) hasil belajar mahasiswa dengan menggunakan metode penyajian verbal pada mahasiswa Program studi Keperawatan Poso.

\begin{tabular}{lcccc}
\hline & Nilai & Nilai Post- Peningkatan & \multirow{2}{*}{ ( } \\
& Pre-test & Test & nilai & \\
\hline Jumlah nilai & 466,66 & 1019,998 & 555,338 & 118,57 \\
Jumlah sampel & 34 & 34 & 34 & \\
Rata - Rata & 13,72 & 29,99 & 16,27 & 118,58 \\
\hline
\end{tabular}

Sumber: Data Primer, 2018

Tabel 4. Peningkatan daya ingat (retensi) hasil belajar mahasiswa dengan menggunakan metode penyajian kombinasi verbal-visual pada mahasiswa Program studi Keperawatan Poso.

\begin{tabular}{lcccc}
\hline & Nilai & Nilai Post- Peningkatan & \multirow{2}{*}{$\%$} \\
& Pre-test & Test & nilai & \\
\hline Jumlah nilai & 573,32 & 2560,00 & 1986,68 & 446,52 \\
Jumlah sampel & 34 & 34 & 34 & \\
Rata - Rata & 16,86 & 75,29 & 58,43 & 346,5 \\
\hline
\end{tabular}

Sumber: Data Primer, 2018 


\section{PEMBAHASAN}

Rata-rata retensi hasil belajar yang menggunakan kombinasi verbal-visual lebih baik dibanding yang hanya menggunakan metode verbal (75,29 dibanding 29,99). Hal ini menunjukkan bahwa hasil belajar mahasiswa dengan menggunakan metode penyajian kombinasi verbal-visual lebih baik daripada metode penyajian verbal. Hal ini diperkuat dengan uji statistik pada taraf kepercayaan 95\% diperoleh $\mathrm{t}$ hitung $=5,70$ lebih besar dari $\mathrm{t}$ Tabel $(2,000)$. Dalam proses pembelajaran, merencanakan metode penyajian belajar sedemikian rupa sangat penting untuk dilakukan karena selain dapat memungkinkan dosen berkreasi secara spontan untuk menyesuaikan dinamika dan reaksi siswa, juga dapat mempertahankan perhatian mahasiswa terhadap materi yang disampaikan selama proses pembelajaran berlangsung.

Untuk mengerti suatu hal dalam diri seseorang harus terjadi proses belajar (motivasi, perhatian, menerima dan mengingat pelajaran, reproduksi, generalisasi, latihan, umpan balik). Dalam proses pengajaran seorang dosen harus dapat memberikan penjelasan yang relevan, menguraikan tentang tujuan, menyebutkan pokok masalah, mengarahkan perhatian murid pada pengetahuan yang telah ada dalam pikiran mereka, mengusahakan struktur yang berarti, menjelaskan struktur, menjaga tingkat perhatian murid, memberi bantuan tambahan, meletakkan dasar untuk transfer, menyisipkan pertanyaan, komentar terhadap reaksi dari pihak murid sehingga dapat mempengaruhi proses belajar. Timbulnya perhatian murid sangat tergantung pada pengajar. Bila pengajar dapat menarik perhatian murid, dengan sendirinya tingkat perhatian mereka pun akan tinggi.

Perhatian murid dalam proses pembelajaran akan meningkat pada lima menit pertama dan menurun dengan cepat pada 20 menit kemudian, tetapi tingkat perhatian murid dinaikkan kembali dengan istirahat singkat yang disisipkan pada saat tertentu, mengajukan pertanyaan, menjawab pertanyaan pendengar atau menunjuk salah seorang pendengar untuk menjelaskan sesuatu ${ }^{(2)}$.

Dalam proses belajar suatu ingatan yang kuat dan kaya sangatlah berjasa. Dalam belajar kita ingin mendapatkan sesuatu dan hal ini tak mungkin tanpa pertolongan dari ingatan manusia $^{(8)}$. Proses retensi/ingatan banyak dipengaruhi oleh berbagai faktor yang meliputi faktor individu, sesuatu yang harus diingat, dan faktor lingkungan. Dari aspek individu, proses mengingat akan lebih efektif apabila individu memiliki minat yang besar, motivasi yang kuat, memiliki metode penyajian tertentu dalam pengamatan dan pembelajaran, memiliki kondisi fisik dan kesehatan yang baik. Dari aspek yang harus diingat adalah sesuatu yang memiliki organisasi dan status yang jelas, mempunyai arti, mempunyai keterkaitan dengan individu, mempunyai intensitas rangsangan yang cukup kuat, dan sebagainya. Dari aspek lingkungan, proses mengingat akan lebih efektif apabila ada lingkungan yang menunjang dan terhindar dari adanya gangguan-gangguan. Salah satu faktor yang 
mempengaruhi daya serap adalah metode penyajian $^{(2)}$.

Proses pembelajaran baik yang menggunakan metode penyajian kombinasi verbal-visual maupun metode penyajian verbal keduanya dapat meningkatkan retensi hasil belajar mahasiswa, tetapi pembelajaran yang menggunakan metode penyajian verbal kurang berhasil untuk dapat meningkatkan retensi hasil belajar. Pembelajaran dengan menggunakan metode penyajian verbal sedikit sekali mendapat perhatian mahasiswa dan partisipasinya terhadap pembelajaran rendah sehingga mahasiswa akan memalingkan perhatiannya kepada objek lain seperti jendela, papan tulis, buku bacaan, dan lain sebagainya $^{(9)}$. Dalam metode penyajian verbal murid harus mengerjakan dua hal yaitu mendengarkan dan membuat catatan, untuk mengadakan variasi guru mengajukan beberapa pertanyaan atau menyuruh mahasiswa mengerjakan sesuatu ${ }^{(1)}$. Pekerjaan yang diberikan sering berupa pekerjaan mekanis dalam rangka merekam apa yang dipaparkan sehingga sedikit sekali memperoleh perhatian mahasiswa dan partisipasinya terhadap pembelajaran rendah ${ }^{(3)}$. Dalam suatu jam pelajaran atau jam kuliah biasa timbul bahaya apabila pendengar menerima terlalu banyak hal baru. Akibatnya hal-hal baru itu menjadi berdesak-desak dan akan menimbulkan kekalutan dalam pikiran pendengar $^{(2)}$. Bagian yang satu akan mendesak bagian yang lain dan menimbulkan kekalutan dalam pikiran pendengar. Keadaan seperti itu akan menimbulkan hasil negatif dan kegiatan belajar yang dilakukan oleh pihak murid tidak akan membuahkan hasil yang berguna. Terkadang ada sebuah informasi yang tidak dapat diakses lagi karena tertutup oleh informasi yang lain yang lebih bermakna. Informasi tersebut tidak hilang hanya tertutup saja $^{(8)}$. Kondisi lupa dapat muncul karena ritme otak atau daya ingat otak terhadap informasiinformasi baru akan hilang terutama pada 20 menit pertama. Kondisi ini akan semakin buruk apabila informasi-informasi tersebut tidak diulangi lagi akan hilang $85 \%$ dalam 24 jam kemudian. Kemampuan mengingat akan menurun setelah tiga hari menjadi $10 \%$ jika menggunakan metode penyajian verbal.

Mutu pengajaran akan meningkat bilamana seorang dapat mempergunakannya dengan tepat. Keterampilan mengajar merupakan suatu hal yang dapat diterapkan oleh setiap orang. Pengajar harus dapat mengarahkan proses belajar sedemikian rupa sehingga dapat menarik perhatian mahasiswa sehingga retensi belajar mahasiswa dapat lebih ditingkatkan ${ }^{(2)}$. Metode penyajian kombinasi verbal-visual dapat membantu dosen memperjelas konsep yang disampaikan dan dapat mempertahankan minat mahasiswa ${ }^{(9)}$. Belajar akan lebih efektif jika pendengaran dan indra penglihatan dapat dikombinasikan. Dengan demikian, saat menjelaskan konsep sebaiknya memberi kesempatan kepada siswa untuk dapat mendengarkan apa yang akan dosen jelaskan dan tunjukkan alat bantu visualnya. Kadang-kadang gambar sederhana yang di gambar dipapan tulis cukup membantu untuk memperjelas konsep yang dibawakan. 


\section{KESIMPULAN DAN SARAN}

Berdasarkan hasil penelitian terdapat perbedaan yang bermakna antara retensi hasil pembelajaran yang menggunakan verbal dibanding kombinasi verbal-visual. Metode penyajian belajar yang sebaiknya digunakan dalam menyampaikan materi selama proses pembelajaran adalah metode penyajian kombinasi verbal-visual daripada metode verbal.

\section{DAFTAR PUSTAKA}

1. Syah M. Psikologi pendidikan dengan pendekatan baru. Bandung: Remaja Rosdakarya, $2002 ; 10-2$.

2. Surya M. Psikologi Pembelajaran Dan Pengajaran. Bandung: Pustaka Bani Quraisy, 2004 ; 73-4

3. Dimiyanti. Belajar dan pembelajaran. Jakarta : Rineka Cipta, 2003 ; 3-19.

4. Djiwandono SEW. Psikologi Pendidikan. Jakarta : Gravindo Persada, 2002 ; 150-7.

5. Departemen Pendidikan Dan Kebudayaan. Mempersiapkan Dan Menggunakan Media Pembelajaran. Jakarta: Departemen Pendidikan Dan Kebudayaan, 2005 ; 1-10.

6. Rudi Susialana, Cepi Riyana. 2007. Media Pembelajaran, Bandung : Wacana Prima.

7. Rora Rizky Wandini. Media Pembelajaran Pendidikan Guru Madrasah Ibtidaiyah (PGMI). J Nizhamiyah. 2016;6(1)

8. Salam B. Cara Belajar Yang Sukses Di Perguruan Tinggi. Jakarta: Rineka Cipta, $2004 ; 4-8$.

9. Arsyad A. Media Pembelajaran. Jakarta: Raja Grafindo Persada, 2005 ; 91-3.

10. Clarke I, Flaherty TB, Yancey M. Teaching the visual learner: The use of visual summaries in marketing education. Journal of Marketing Education. 2006;28(3). 